describing the unusual presentation of this condition in a Caucasian female, the first case described in Ireland.

A 48-yr-old female attended outpatient clinic for her fifth annual asthma review. She had experienced four infective exacerbations in the previous 12 months and reported recent large-volume sputum production, associated with worsening dyspnoea on exertion. Computed tomography (CT) thorax scan revealed bronchiectasis. The patient was treated over the subsequent 3 yrs for exacerbations of asthma and bronchiectasis.

Over this period, her pulmonary function tests began to show severe small airways obstruction. The patient was now experiencing severe dyspnoea on minimal exertion and was becoming unresponsive to inhaled bronchodilators and highdose oral steroids. Pulmonary function testing at this point revealed airflow obstruction, with a reduced forced expiratory volume in one second (FEV1) of $1.67 \mathrm{~L} \cdot \mathrm{min}^{-1}$ (66\% predicted), a forced vital capacity (FVC) of $2.31 \mathrm{~L} \cdot \mathrm{min}^{-1}$ (78\% pred) and a diffusing capacity of the lung for carbon monoxide that was $49 \%$ pred. Bronchiolitis/bronchiolectasis was now suspected. Further CT scanning demonstrated more extensive changes of bronchiectasis, associated with fine nodular opacities in both lung bases. In contrast to the usual pattern, this had a more distal distribution. The combination of these CT findings and small airways obstruction without large airway involvement on pulmonary function testing prompted referral for thoracoscopic lung biopsy. Exhaustive analysis of the tissue, including a second opinion from an international centre, revealed a histological diagnosis of diffuse panbronchiolitis. The patient was commenced on erythromycin $500 \mathrm{mg}$ b.i.d. with a dramatic response. Macrolide treatment was continued over the next 2 yrs with a significant reduction in sputum production, improvement in spirometry (FEV1 $2.35 \mathrm{~L} \cdot \mathrm{min}^{-1}$ and FVC $\left.3.9 \mathrm{~L} \cdot \mathrm{min}^{-1}\right)$, resolution of wheeze and improved exercise tolerance comparable to that of $10 \mathrm{yrs}$ earlier. Over the next few years, attempts were made to reduce erythromycin therapy with little success. The patient's debilitating symptoms always returned. She remained on erythromycin $500 \mathrm{mg}$ b.i.d. maintenance dose and managed to complete a 200-mile sponsored walk.

This case highlights the importance of considering this diagnosis or certainly the forme fruste mentioned by POLETTI et al. [1] in their review, in the group of patients with asthma and/or bronchiectasis who show no improvement with conventional therapies, including high-dose oral steroid, and who actually decline rapidly despite treatment. Something as simple as erythromycin could be the difference between severe morbidity or death and walking 200 miles!

\section{E.E. McGrath, A.M. McLaughlin and M.X. FitzGerald \\ St. Vincent's University Hospital Dublin, Dublin, Ireland.}

\section{STATEMENT OF INTEREST}

None declared.

\section{REFERENCES}

1 Poletti V, Casoni G, Chilosi M, Zompatori M. Diffuse panbronchiolitis. Eur Respir J 2006; 28: 862-871.

DOI: $10.1183 / 09031936.00157606$

\title{
Exposure to second-hand smoke: a population-based survey in Spain
}

\section{To the Editors:}

In 1972, a US Surgeon General's report, "The Health Consequences of Smoking", addressed the topic of passive smoking [1]. More than three decades later, another Surgeon General's report, "The Health Consequences of Involuntary Exposure to Tobacco Smoke", concluded that a causal relationship exists between second-hand smoke (SHS) exposure experienced by lifelong nonsmokers and several diseases, including lung cancer and coronary heart disease [2].

Despite the report's findings, legislation promoting population protection against this ambient carcinogen [3] has been slow to take hold globally. The exposure of the Spanish population remains unknown and existing data on prevalence of exposure are limited to selected areas or specific populations [4, 5]. An anti-smoking law was recently implemented in Spain [6], with the aim of combating this health problem by decreasing population exposure to SHS in employment and public settings.

Between December 2004 and January 2005, we developed a study on tobacco use and SHS exposure among the general population in the northern Spanish region of Galicia. The source of sampling was the regional healthcare card system, which covers $97 \%$ of the population. The study yielded SHS exposure data collected in Galicia, based on a representative population sample. Galicia is located in the north-west of Spain and was estimated to have a population of 2.7 million in 2004, with a smoking prevalence of $29 \%$ (95\% confidence interval $27.8-30.2 \%$ ). People who smoked daily or occasionally were classified as smokers.

One of the study's objectives was to estimate exposure to SHS in the general population, aged 16-74 yrs. The sampling unit was the individual and the sample $(n=6,492)$ was representative by sex and was divided into age groups: 16-24, 25-44, and 45-74 yrs. Data collection was carried out primarily through telephone interviews (90\%); however, $10 \%$ of the interviews were conducted in person, in order to avoid under-representation of people without phone facilities.

The Galician Smoking Interview Survey included several questions that aimed to estimate SHS exposure within the three microenvironments most commonly frequented by the 
TABLE 1 Prevalence of exposure to second-hand smoke in three settings

\begin{tabular}{|c|c|c|c|c|c|c|c|c|}
\hline & Subjects & Home only & Work only & $\begin{array}{l}\text { Public places } \\
\text { only }\end{array}$ & $\begin{array}{l}\text { Home and } \\
\text { work }\end{array}$ & $\begin{array}{l}\text { Home and public } \\
\text { places }\end{array}$ & $\begin{array}{l}\text { Work and } \\
\text { public places }\end{array}$ & $\begin{array}{c}\text { Home, work } \\
\text { and public places }\end{array}$ \\
\hline Total & $6411 / 4542$ & $7.1(6.3-8.0)$ & $6.0(5.2-6.9)$ & $28.5(27.3-29.8)$ & $2.0(1.5-2.5)$ & $11.7(10.8-12.5)$ & $25.3(23.9-26.8)$ & $12.5(11.4-13.6)$ \\
\hline Males & & $3.6(2.9-4.4)$ & $5.9(4.8-6.9)$ & $34.7(32.9-36.5)$ & $1.7(1.1-2.3)$ & $11.4(10.0-12.3)$ & $25.4(23.5-27.3)$ & $12.1(10.7-13.5)$ \\
\hline $16-24 \mathrm{yrs}$ & $1206 / 1092$ & $2.0(1.2-2.8)$ & $2.8(1.8-3.8)$ & $25.8(23.3-28.3)$ & $1.0(0.4-1.6)$ & $17.8(15.7-20.0)$ & $31.8(29.0-34.5)$ & $21.3(18.8-23.9)$ \\
\hline $25-44$ yrs & $1181 / 1034$ & $2.3(1.5-3.2)$ & $4.7(3.4-6.0)$ & $36.4(33.7-39.2)$ & $1.6(0.9-2.4)$ & $12.1(10.2-13.9)$ & $27.1(24.2-29.9)$ & $10.8(8.8-12.7)$ \\
\hline $45-74$ yrs & $1059 / 500$ & $5.2(3.8-6.6)$ & $9.4(6.9-12.0)$ & 35.9 (32.9-38.8) & $2.2(0.9-3.5)$ & $8.4(6.7-10.1)$ & $19.2(15.7-22.6)$ & $9.0(6.3-11.8)$ \\
\hline Females & & $10.9(9.4-12.3)$ & $6.3(4.8-7.7)$ & $22.0(20.3-23.8)$ & $2.4(1.6-3.3)$ & $12.2(10.9-13.5)$ & $25.3(23.0-27.6)$ & $13.1(11.3-14.8)$ \\
\hline $16-24$ yrs & $1214 / 1031$ & $2.4(1.5-3.3)$ & $1.7(0.9-2.4)$ & $24.6(22.2-27.0)$ & $2.0(1.1-2.8)$ & $19.2(16.9-21.4)$ & $32.3(29.4-35.2)$ & $22.5(20.0-25.1)$ \\
\hline $25-44$ yrs & $1159 / 749$ & $8.3(6.7-9.9)$ & $7.4(5.5-9.3)$ & $28.1(25.5-30.7)$ & $2.4(1.3-3.5)$ & $14.8(12.8-16.8)$ & $25.1(21.9-28.2)$ & $11.2(8.7-13.8)$ \\
\hline $45-74$ yrs & $592 / 136$ & $15.9(12.9-18.9)$ & $8.8(3.9-13.6)$ & $15.8(12.7-18.8)$ & $3.1(0.1-6.0)$ & $7.5(5.4-9.7)$ & $17.6(11.1-24.1)$ & $6.5(2.6-10.3)$ \\
\hline Nonsmokers & & $7.5(6.5-8.6)$ & $6.8(5.6-7.9)$ & $29.3(27.7-30.8)$ & $1.6(1-2.1)$ & $8.7(7.8-9.6)$ & $25.7(23.8-27.5)$ & $8.8(7.7-9.9)$ \\
\hline Males & $2199 / 1637$ & $3.0(2.2-3.8)$ & $6.5(5.1-7.9)$ & $36.7(34.4-38.9)$ & $1.4(0.8-2.1)$ & $8.9(7.7-10.2)$ & $25.2(22.8-27.6)$ & $8.4(7.0-9.8)$ \\
\hline Females & $2075 / 1273$ & $11.6(9.7-13.4)$ & $7.2(5.2-9.1)$ & $22.6(20.6-24.7)$ & $1.8(0.8-2.7)$ & $8.4(7.1-9.7)$ & $26.3(23.4-29.1)$ & $9.3(7.5-11.2)$ \\
\hline Smokers & & $6.2(4.9-7.5)$ & $4.6(3.4-5.8)$ & $26.7(24.5-28.8)$ & $2.8(1.9-3.8)$ & $19.0(17.1-20.9)$ & $24.7(22.4-27.1)$ & 19.5 (17.3-21.6) \\
\hline Males & $1247 / 989$ & $4.8(3.3-6.3)$ & $4.8(3.2-6.3)$ & $30.9(28.1-33.8)$ & $2.2(1.1-3.2)$ & $15.3(13.1-17.5)$ & $25.7(22.7-28.7)$ & $18.4(15.7-21.1)$ \\
\hline Females & $890 / 643$ & $8.5(6.2-10.8)$ & $4.2(2.4-6.0)$ & $20.0(16.9-23.1)$ & $4.0(2.1-5.9)$ & $24.7(21.2-28.1)$ & $23.0(19.2-26.8)$ & $21.4(17.9-25.0)$ \\
\hline
\end{tabular}

Data are presented as \% (95\% confidence interval) or number of subjects whose answers covered all three locations/number of subjects whose answers covered only home and public places. The denominators in the prevalence calculations varied accordingly.

population: work, house, and public places. Questions referred to the week prior to the interview.

Results indicate that $74.6 \%(73.2-75.9 \%)$ of the Galician population were exposed to SHS: $80.5 \%(79.0-82.1 \%)$ of males and $68.2 \%(66.1-70.4 \%)$ of females. More detailed results are shown in table 1.

The Barcelona Health Interview Survey 2000, a study developed in Spain applying similar measures of SHS exposure, yielded similar results. A $69.7 \%$ prevalence of SHS exposure was found in an urban population aged 15-64 yrs, taking into consideration exposure at home and work. In the USA, where restrictive laws for decreasing exposure to SHS preceded similar laws in Spain, the prevalence of exposure was lower ( $\sim 40 \%$ in adults) [2].

Taking into consideration all biases related to second-hand smoke exposure measurement using questionnaires, as well as acceptable agreement with levels of cotinine [7] and the fact that self-declared exposure often underestimates actual exposure [8], the problem is likely to be even more troublesome than this study indicates. These results prove that second-hand smoke poses an important public health problem in Galicia.

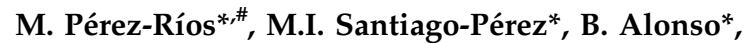

\section{A. Malvar* and X. Hervada*}

*Directorate-General for Public Health, Galician Regional Health Authority, and "Dept of Preventive Medicine and Public Health, University of Santiago de Compostela, Santiago de Compostela, Spain.

\section{REFERENCES}

1 US Department of Health, Education, and Welfare. The Health Consequences of Smoking: a Report of the Surgeon General. Washington, US Department of Health, Education, and Welfare, 1972.

2 US Department of Health and Human Services. The Health Consequences of Involuntary Exposure to Tobacco Smoke: a Report of the Surgeon General. Washington, US Department of Health and Human Services, 2006.

3 Environmental Protection Agency. Respiratory Health Effects of Passive Smoking: Lung Cancer and Other Disorders. Washington, US Environmental Protection Agency, 1992.

4 Nebot M, López MJ, Tomás Z, Ariza C, Borrell C, Villalbí JR. Exposure to environmental tobacco smoke at work and at home: a population based survey. Tob Control 2004; 13: 95-96.

5 Twose J, Schiaffino A, Garcia M, Marti M, Fernandez E. Prevalence of exposure to environmental tobacco smoke in a urban population. Med Clin (Barc) 2004; 123: 496-498.

6 Fernandez E. Spain: going smoke free. Tob Control 2006; 15: 79-80.

7 Jaakkola MS, Jaakkola JJ. Assessment of exposure to environmental tobacco smoke. Eur Respir J 1997; 10: 2384-2397.

8 Repace JL. Exposure to secondhand smoke. In: Ott WR, Steinemann AC, Wallace LA. Exposure Analysis. Boca Raton, Taylor \& Francis Group, 2007; pp. 201-231.

DOI: $10.1183 / 09031936.00158006$ 